\title{
A regional programme to collect plasma for preparation of human immunoglobulin anti-rabies
}

\author{
RJ CRAWFORD, M MORGAN, AND R MITCHELL \\ From Glasgow and West of Scotland Blood Transfusion Service, at Law Hospital, Carluke, UK
}

SUMMARY We identified over 100 recipients of rabies vaccine (human diploid cell vaccine) and recruited them as plasma donors. Some were plasmapheresed at static centres, others by mobile teams. The operation of these teams is described in detail. No plasma was sent to the Fractionation Centre until the date of vaccination had been checked. Assay results showed that the majority of plasma collected between four and 20 weeks after the second dose of vaccine contained 6 or more IU $/ \mathrm{ml}$.

Rabies may return to Britain. In the past few years rabies has become endemic among the wild life of northern France with the constant risk that domestic animals will be bitten and the disease transmitted to man.

Until recently rabies vaccines were poorly immunogenic, and vaccination did not give a satisfactory degree of lasting immunity. ${ }^{1}$ In any case the side effects of vaccination made prophylactic vaccination undesirable except in people with a very high risk of becoming infected.

The newer vaccines, produced in cell culture, are both more potent and safer than either the brain tissue or duck embryo vaccines. The Health Departments have made a limited amount of cell culture vaccine available for pre-exposure vaccination of customs and excise officers and other people likely to be exposed to imported rabies.

For the first time the blood transfusion services have had a ready supply of potential donors with high levels of circulating anti-rabies antibody. Turner $^{2}$ has shown that after rabies vaccination with cell culture vaccines high levels of IgG neutralising antibody are produced. IgG but not IgM antibodies gave passive protection to mice in his experiments.

The World Health Organization ${ }^{3}$ advises all countries to ensure a supply of anti-rabies immunoglobulin. Human products are preferable to those made from animals. ${ }^{1}$ Although the rapid response to active immunisation with cell culture vaccines

Received for publication 23 July 1979 observed by Kuwert and his colleagues may reduce the future need for passive immunisation in the treatment of people exposed to rabies, immunoglobulin was used by Bahmanyar et al. ${ }^{4}$ in their successful trial of human diploid cell culture vaccine obtained from the Institut Mérieux.

We describe the programme of donor recruitment and plasmapheresis operating in the west of Scotland.

We collected 180 donations of anti-rabies plasma in 1978 and 160 donations in the first six months of 1979. Unsatisfactory donations have been excluded from these totals.

\section{Methods and volunteers}

RECRUITMENT

All blood donor volunteers were questioned about recent immunisations. Any who gave a history of vaccination against rabies were invited to join the plasmapheresis programme. Because the majority of pre-exposure vaccinations are given at work the volunteers were asked to collect names of any workmates who had been vaccinated who wanted to join the programme.

We also contacted departments likely to be involved in rabies vaccination and asked them to supply details of vaccinees who were willing to be plasmapheresed.

We received notifications from the following sources:

Community medicine specialists

Senior police surgeon

University department of veterinary medicine

Regional virus laboratory

Recipients of vaccine 
The occupations of the volunteers were: veterinary medicine (university staff); customs and excise officers; cargo handlers (international airports); police dog handlers; dog home workers; dog breeders; and taxidermists.

In addition, one post-exposure vaccinee was recruited. He had not received immunoglobulin. A high proportion of the people approached volunteered though some were rejected on medical grounds.

\section{ORGANISATION}

It is our practice to plasmapherese our donor panel at six-weekly intervals. This avoids depleting the donor's plasma protein levels and (for daytime donors) keeps lost working time to an acceptable level. ${ }^{5}$ Most of the donors were brought either to our static donor centre in central Glasgow or to the Regional Transfusion Centre at Law (near Carluke, Lanarkshire). Other arrangements were necessary to collect blood from donors based at Grangemouth, a port $40 \mathrm{~km}$ from Glasgow. Initially, one of our mobile blood-collecting vehicles was used in association with our mobile blood-processing laboratory. Later it became possible to use a day ward in a nearby hospital (Falkirk and District Royal Infirmary). We are currently centrifuging and separating donations in the hospital blood bank, making the mobile laboratory available for other purposes.

A number of customs and excise officers manning scattered posts along the extensive Galloway coast were vaccinated. These donors were transported to Dumfries and Galloway Royal Infirmary $(118 \mathrm{~km}$ from Glasgow) for plasmapheresis. Beds were provided in the hospital and donations were processed in the hospital blood bank. This system of plasma collection is currently being introduced in a third outlying hospital.

\section{VACCINATION SCHEDULE}

The vaccine used was Mérieux Inactivated Rabies Vaccine (Servier Laboratories Ltd). It is a lyophilised, stabilised suspension of inactivated Wistar virus strain PM/WI 38 1503-3M cultured on human diploid cells and inactivated by beta-propiolactone. Two doses of vaccine are given one month apart. A reinforcing dose is given a year later and may be followed by further reinforcing doses according to the degree of exposure.

\section{PLASMAPHERESIS SCHEDULE}

For practical reasons we did not adhere strictly to the schedule but, when possible, we collected plasma between one and six months after the second and third doses of vaccine. This gave us two five-month periods per donor.
ASSAYS

These were carried out by Dr GS Turner, Lister Institute, Elstree, by the mouse protection method.

We hope in future that an in vitro virus neutralisation assay may become available.

\section{INVENTORY SYSTEM}

All anti-rabies plasma was stored at $-30^{\circ} \mathrm{C}$ and none was sent for fractionation until the donor's history and date of vaccination had been checked by one of us. When assay results were awaited donations were stored until results were available.

\section{Results}

In early 1978 assays were carried out on 115 donations. Later, practical difficulties prevented our having any assays done at all. The results are divided into categories: over $6 \mathrm{IU} / \mathrm{ml}$ (good), $6 \mathrm{IU} / \mathrm{ml}$ (borderline), and under $6 \mathrm{IU} / \mathrm{ml}$ (unsuitable for fractionation to specific immunoglobulin). The Table shows the results of the assays divided according to the number of weeks since the second dose of vaccine. No results are available for donations collected after the third dose.

\section{Discussion}

Many transfusion services rely on virologists, public health authorities, and general medical practitioners for notification of people who may become suitable donors of antibodies for specific immunoglobulin production. Particular occupational groups are more likely than others to have certain antibodies. Examples are the high level of anti-tetanus antibodies in slaughterhouse workers (unpublished observations) and of anti-vaccinia in recently vaccinated servicemen.

We have successfully combined the first approach with the second. Thus, a substantial proportion of rabies vaccinees have been asked either by the vaccinators or by workmates if they were willing to volunteer. It is uncertain how many people have received the vaccine but over 100 people have volunteered for the anti-rabies programme so far.

Our mobile blood-processing laboratory and self-contained mobile donor centres have been used in combination to allow plasmapheresis of donors who could not reasonably be asked to travel to our static centres. This arrangement minimised our dependence on outside help, but the mobile centres are inconvenient for plasmapheresis because of their compact design and because there is no arrangement for donors to sit up and talk; the supine position is acceptable for 10 minutes during a standard blood donation but donors become bored if left for longer 


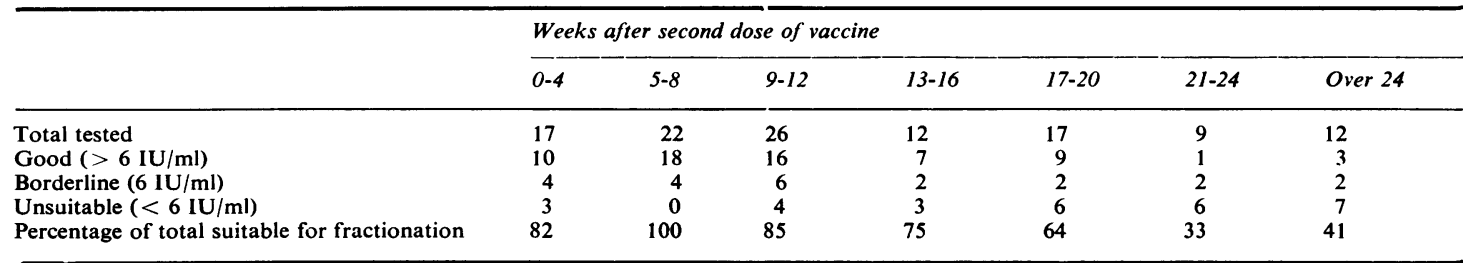

periods. A detailed account of these vehicles is to be published later but information is available on request.

We have demonstrated that a well-trained, mobile, blood-collecting team is quite capable of carrying out plasmapheresis in a district general hospital far from its base if careful arrangements are made in advance. The help of the two hospital blood banks has allowed us to carry out plasmapheresis without deploying the mobile blood processing laboratory whose main purpose is to prepare platelet concentrates and fresh frozen plasma from whole blood as soon as possible after donation.

The inventory system has worked well and has ensured that all plasma sent for specific immunoglobulin preparation has in fact been taken from well vaccinated donors within the five-month optimum periods.

We gave considerable thought to the timing of plasmapheresis. The assays confirmed initial fears that antibody responses would be less than ideal if plasma were collected before the third dose of vaccine had been given. However, we knew that only a limited number of people would be vaccinated and that there would be very few pre-exposure vaccinations in the following years unless rabies became a serious clinical problem. By that time it would be too late as the anti-rabies immunoglobulin would be required urgently for post-exposure cases. We also had some doubts about how many vaccinees would receive their third dose but these fears proved unfounded.

The assay results illustrate the prompt antibody response to two doses of cell culture vaccine and show sustained high levels of antibody for 20 weeks after the second dose in about two-thirds of donors. A lower proportion of plasma collected later had satisfactory antibody levels and should not be used for specific immunoglobulin preparation unless assays of neutralising activity are available.These require live rabies virus, and practical difficulties have prevented our obtaining assays on donations taken after the third dose of vaccine.

It is most important to emphasise that the antibody levels required for immunoglobulin preparation are much higher than those required for protection of the individual. Thus, we have every reason to believe that the donors have a good level of personal immunity even when their plasma contains less than $6 \mathrm{IU} / \mathrm{ml}$ of neutralising antibody.

We are grateful to Dr GS Turner for the assays, to Dr JG Selwyn and his staff for facilities at Dumfries, and to Dr DM Ramsay and his staff for facilities at Falkirk. We thank our many colleagues who have contributed to the programme but most of all we want to thank our loyal and generous blood donors.

\section{References}

${ }^{1}$ Kuwert E K, Werner J, Marcus I, Cabasso V J. Immunization against rabies with rabies immune globulin, human (RIGH) and a human diploid cell strain (HDCS) rabies vaccine. $J$ Biol Stand 1978; 6: 211-219.

${ }^{2}$ Turner G S. Immunoglobulin (IgG) and (IgM) antibody responses to rabies vaccine. J Gen Virol 1978; 40: 595-604.

${ }^{3}$ World Health Organization Expert Committee on Rabies, 6th report. WHO Techn Rep Ser 1973; No. 523.

${ }^{4}$ Bahmanyar M, Fayaz A, Nour-Salehi S, Mohammadi M, Koprowski H. Successful protection of humans exposed to rabies infection: Post exposure treatment with the new human diploid cell rabies vaccine and antirabies serum. $J$ Am Med Ass 1976; 236: 2751-2754.

${ }^{5}$ Lundsgaard-Hansen P. Volume limitations of plasmapheresis. Vox Sang 1977; 32: 20-25.

Requests for reprints to: Dr R Mitchell, Glasgow and West of Scotland Blood Transfusion Service, Law Hospital, Carluke, Lanarkshire ML8 5ES, UK. 